\title{
A Contribuição da RNP para a Conformidade dos Provedores de Identidade da Federação CAFe ao SIRTFI
}

\author{
Cristiane Fernandez Rodrigues, Luciano Fernandes da Rocha, Rui de Quadros \\ Ribeiro
}

Rede Nacional de Ensino e Pesquisa (RNP)

SAS, Quadra 5, Lote 6, Bloco H, $7^{\circ}$ Andar - Brasília - DF

\{cristiane.rodrigues, luciano.rocha\}@rnp.br, rui.ribeiro@cafe.rnp.br

\begin{abstract}
Resumo. A Federação CAFe é um serviço da RNP e é largamente utilizada por docentes, discentes e pesquisadores de todo Brasil. Nesse artigo serão descritos os esforços para a elaboração de uma avaliação de segurança bem como a busca na conformidade ao SIRTFI.
\end{abstract}

\section{Federação CAFe}

A Comunidade Acadêmica Federada (CAFe) é uma federação de identidade, baseada em SAML, composta por instituições de ensino e pesquisa do Brasil. O serviço é mantido pela Rede Nacional de Ensino e Pesquisa (RNP), permitindo que com apenas uma conta os usuários possam acessar os serviços de sua própria instituição e aqueles oferecidos por outras instituições que participam da federação, eliminado assim a necessidade de múltiplas senhas de acesso e cadastros [Rede Nacional de Ensino e Pesquisa, 2019].

\section{Segurança em federações de identidade}

A discussão de mecanismos que contribuam para o aumento da segurança em federações de identidade é recorrente. A seguir serão apresentadas duas ações que buscam atingir este objetivo.

\subsection{Definição de requisitos de segurança para a $\mathrm{CAFe}$}

Tendo como base as exigências correntes para adesão à CAFe, bem como as melhores práticas de segurança da informação e gestão de identidade, foram elencados treze requisitos de segurança. Tais requisitos (Figura 1) servem como linha de base e serão avaliados com finalidade de mensurar a maturidade dos Provedores de Identidade.

\begin{tabular}{|l|l|c|l|}
\hline & REQUISITOS & & REQUISITOS \\
\hline R01 & Gestão e Armazenamento de logs do IdP & R08 & Processo de aceite da Política de Uso Aceitável do Serviço para todos os usuários \\
\hline R02 & Processo de sincronização do servidor com um servidor NTP & R09 & Processo para gestão de Identidade \\
\hline R03 & Processo de atualização dos responsáveis pelo IdP e por segurança da informação & R10 & Os servidores devem ser específicos para cada aplicação (físico ou virtual) \\
\hline R04 & Processo de mudança & R11 & Política de senha \\
\hline R05 & Processo de gestão de patches & R12 & Política de backup \\
\hline R06 & Processo para Identificação, análise e tratamento de incidentes (CSIRT) & R13 & Gestão de vulnerabilidades \\
\hline R07 & Política de Uso Aceitável do serviço atualizada e disponibilizada a todos os usuários & & \\
\hline
\end{tabular}

Figura 1. Requisitos de segurança da informação para a CAFe 


\subsection{SIRTFI}

O framework SIRTFI busca o estabelecimento de uma rede para tratamento de incidentes de segurança no escopo de federações de identidade [GÉANT Association, 2019]. O uso do SIRTFI é voluntário e, para tanto, a instituição interessada deve se autodeclarar em conformidade aos requisitos existentes.

\subsection{Correlação entre os requisitos de segurança da CAFe e o SIRTFI}

Fazendo uma análise comparativa é possível identificar que os requisitos do SIRTFI representam um subconjunto dos requisitos de segurança da CAFe. Dessa forma, ao estar em conformidade ao SIRTFI haverá $70 \%$ de conformidade aos requisitos de segurança da CAFe. Tal situação contribui para o aumento do nível de maturidade individual das instituições bem como da federação como um todo.

\section{Papel da RNP como facilitador na implementação dos controles de segurança da informação na CAFe}

Com a finalidade de apoiar as instituições de ensino e pesquisa a RNP elaborou um conjunto de documentos modelos, contemplando normas, procedimentos operacionais e termos de forma a atender aos diversos tipos de instituições vinculadas à CAFe. Os documentos apresentam um passo a passo para a implementação dos dezesseis requisitos apresentados no SIRTFI.

\section{Próximos passos e a avaliação cruzada}

Em breve a RNP iniciará um projeto-piloto com algumas instituições no qual serão disponibilizados os documentos modelos. Adicionalmente irá prestar apoio consultivo para a busca de conformidade ao SIRTFI, bem como para a elaboração de um plano de ação de conformidade com os requisitos de segurança da CAFe. O piloto validará ainda um modelo de avaliação cruzada no qual uma instituição já conforme auxiliará uma instituição que esteja em processo de conformidade, criando assim uma rede de apoio.

\section{Considerações finais}

A adoção das melhores práticas de segurança da informação é um movimento observado nos mais diversos setores, tanto no Brasil quanto mundialmente. A busca de conformidade ao SIRTFI pelos Provedores de Identidade da CAFe apoiará o aumento da maturidade da Federação, na medida em que contribuirá para a diminuição dos riscos relacionados ao vazamento de informações e controles relacionados à segurança da informação.

\section{Referências}

GÉANT Association - REFEDS / SIRTFI. Disponível em: <https://refeds.org/sirtfi >. Acesso em: 20 de julho de 2019.

Rede Nacional de Ensino e Pesquisa - Serviço Avançado CAFe. Disponível em: $<$ https://www.rnp.br/servicos/servicos-avancados/cafe $>$. Acesso em 20 de julho de 2019. 